Published in final edited form as:

Org Lett. 2019 September 06; 21(17): 6790-6794. doi:10.1021/acs.orglett.9b02406.

\title{
Synthesis of Branched Triubiquitin Active-Site Directed Probes
}

\author{
Jiaan Liu ${ }^{\dagger}$, Yanfeng $\mathrm{Li}^{\dagger}$, Kirandeep K. Deol ${ }^{\dagger}$, Eric R. Strieter ${ }^{\star}, \dagger \neq$ \\ tDepartment of Chemistry, University of Massachusetts, Amherst, Massachusetts 01003, United \\ States \\ ‡Department of Biochemistry and Molecular Biology, University of Massachusetts, Amherst, \\ Massachusetts 01003, United States
}

\begin{abstract}
Active-site directed probes are powerful tools for studying the ubiquitin conjugation and deconjugation machinery. Branched ubiquitin chains have emerged as important proteasometargeting signals for aggregation-prone proteins and cell cycle regulators. By implementing a new synthetic strategy for the electrophilic warhead, we herein report on the generation and reactivity of a series of branched triubiquitin active-site directed probes. These new tools can be used to dissect the molecular basis of branched chain assembly and disassembly.
\end{abstract}

\section{Graphical Abstract}

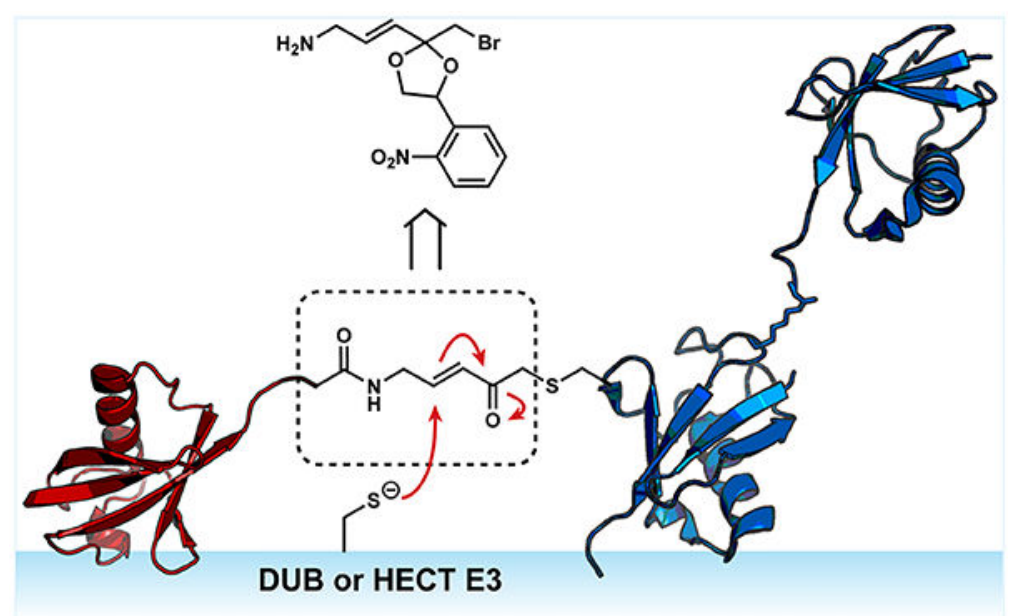

Ubiquitin (Ub) chains provide highly nuanced mechanisms of cellular regulation. ${ }^{1,2}$ Once a protein is modified with $\mathrm{Ub}, \mathrm{Ub}$ itself can serve as the substrate to afford polymeric $\mathrm{Ub}$ chains. During this elongation process, one of seven amino groups of Ub (Lys6, Lys11, Lys27, Lys29, Lys33, Lys48, and Lys63) or its amino terminus (Met1) can be conjugated to

"Corresponding Author: estrieter@chem.umass.edu.

Supporting Information

The Supporting Information is available free of charge on the ACS Publications website at DOI: 10.1021/acs.or-glett.9b02406. Synthetic protocols, protein expression information, enzyme assays, and characterization of crucial inter-mediates (PDF) 
the C-terminus of another ubiquitin molecule. ${ }^{3-5}$ Moreover, a single Ub moiety can be modified at more than one site, creating a branch point. Thus, in addition to chain length, there is tremendous variability in chain architecture. Effector proteins within the Ub signaling network, i.e., deubiquitinases (DUBs) $)^{6-8}$ and "reader" proteins containing Ubbinding domains, ${ }^{9}$ are capable of exploiting subtle differences in the orientation and spacing of Ub subunits present in different chains to control the net flux through biochemical pathways. With the immense diversity of chains and the number of enzymes involved in $\mathrm{Ub}$ signaling, however, there are still many questions that remain unresolved regarding the assembly, recognition, and removal of specific chain types.

Active-site directed probes (also referred to as activity-based probes; ABPs) have been particularly effective as tools for dissecting the Ub conjugation and deconjugation machiner. 10,11 The basic design of an ABP includes a recognition element that directs the probe to its target and an electrophilic warhead that reacts with an enzyme active site to afford a covalent adduct. ${ }^{12,13}$ The classic Ub-based ABPs use monoUb as the recognition element. ${ }^{14-21}$ These ABPs have been instrumental in the discovery of $\mathrm{DUBs}^{22-27}$ and elucidating how substrate engagement induces conformational changes in DUBs that are conducive to catalysis. ${ }^{28-34}$ More recently, di- and tri-Ub-based probes have been added to toolbox. ${ }^{35-39}$ The utility of these probes has been illustrated by biochemical and structural studies that have helped illuminate the molecular details underlying the linkage selectivity of DUBs. ${ }^{34,39,40}$

Despite the impressive advances in Ub ABPs, there is still a need for additional tools. Recent studies have shown that branched Ub chains provide a unique signal for targeting proteins to the proteasome for degradation. During mitosis, for instance, the cullin-RING E3 ligase $\mathrm{APC} / \mathrm{C}$ (anaphase promoting complex/cyclosome) collaborates with the E2 conjugating enzymes UBE2C and UBE2S to assemble Lys11/Lys48-linked branched chains on several cell cycle regulators. ${ }^{41}$ In response to proteotoxic stress, nascent and aggregation-prone proteins are also modified with Lys11/Lys48-linked branched Ub chains to promote their clearance. ${ }^{42}$ In this case, branched chains are synthesized, in part, by the HECT E3 ligase UBR5. UBR5 can also introduce Lys48 branch points on pre-existing Lys63 chains to redirect a substrate to the proteasome for degradation. ${ }^{43}$ How E3s assemble branched chains is unclear. ${ }^{44,45}$ Access to branched chain ABPs would help address this problem. Branched chain ABPs can also be used to understand how this architecture affects the activity of DUBs. ${ }^{46,47}$

Our approach focused on a two-step sequence starting from two different Ub variants. The idea was to site-specifically couple a set of di-Ubs to a Ub C-terminally modified with an abromo-vinylketone (BVK) moiety to afford tri-Ub derivatives containing a native isopeptide bond on one side of the branch point and a Michael acceptor on the other (Scheme 1). Linkage-specific enzymes provide a powerful set of tools to assemble dimers with amino acid substitutions in specific subunits. ${ }^{48}$ With Cys introduced at specific sites in lieu of Lys, we can couple dimers to Ub-BVK using standard Cys thiolate substitution chemistry.

To synthesize the Ub-BVK derivative we turned to previous work ${ }^{37}$ in which a latent form of BVK was coupled to Ub-MESNA prior to deprotection under acidic conditions (4 mM p$\mathrm{TsOH}, 54 \%$ (v/v) TFA). In our hands, however, we observed extensive hydrolysis during the 
deprotection of the ethylene glycol ketal, resulting in the formation of $\mathrm{Ub}_{1-75}$, thereby precluding the generation of sufficient quantities of the tri-Ub probe. To overcome these challenges, we sought to devise a slightly different synthetic route to Ub-BVK.

Our synthesis commenced with a cross-metathesis reaction between $\mathrm{N}$-allylphthalimide (2) and methyl vinyl ketone using the Hoveyda-Grubbs second-generation catalyst and Lewis acid $\mathrm{Cy}_{2} \mathrm{BCl}$ (Figure 1). ${ }^{49}$ This reaction reproducibly furnished 3 in approximately $40 \%$ yield. After a-bromination, we subjected ketone 4 to ketalization conditions with 1-(2nitrophenyl)-1,2-ethanediol (5). We reasoned the photolability of the $o$-nitrophenyl group would enable deprotection under milder conditions relative to those used for the ethylene glycolbased ketal. With the photolabile ketal in place, the amino group was unveiled using methyl hydrazine to give 6 and coupled to $\mathrm{Ub}_{1-75}-\mathrm{MESNa}$ (7) to obtain 8 . We found that the aminolysis reaction occurs readily with only 30 -fold excess of amine 6 relative to $\mathrm{Ub}_{1-75^{-}}$ MESNa, minimizing the loss of material.

Irradiation of the resulting photolabile Ub-BVK derivative (8) was examined at different pHs. Reactions were monitored by MALDI-TOF mass spectrometry (MS) (Figure S3). Under all conditions, we detected significant amounts of Ub-BVK (9). Although hydrolysis still occurs, the amount of $\mathrm{Ub}_{1-75}$ is still markedly less than what we observed with ethylene glycol as a protecting group. Moreover, compared to the deprotection of the ethylene glycol ketal, which affords at least four products with Ub-BVK as a minor species, removal of the photolabile ketal resulted in Ub-BVK as the major product.

With Ub-BVK in hand, we sought to assemble branched tri-Ub probes. We started with diUb variants containing $\mathrm{K} 6 \mathrm{C}, \mathrm{K} 48 \mathrm{C}$, or $\mathrm{K} 63 \mathrm{C}$ substitutions in the proximal subunit (10a-d). Upon mixing Ub-BVK with the Cys-containing dimers, we observed robust trimer formation (Figure 2). MS analysis confirmed the generation of each probe (Figures 2 and S6).

Next, we investigated the reactivity of the branched tri-Ub probes toward cysteine-dependent DUBs. OTUB1 is Lys48-specific DUB ${ }^{50}$ in the ovarian tumor (OTU) subfamily and is capable of rapidly cleaving the Lys48 linkage within branched trimers. In accord, we found that OTUB $1 *$-a more active version with the E2 UBE2D2 genetically fused to the Nterminus ${ }^{51}$-reacts with the branched probes 11a and 11b (Figure 3A). The catalytic Cys residue is critical for covalent complex formation, as higher molecular weight bands are not observed with the inactive C91A variant (Figure 3A). OTUB1* also displays selectivity for the electrophilic warhead at position-48. When other non-Lys48 residues are replaced with the warhead (e.g., Lys6 in 11c or Lys63 in 11d*), complex formation is not observed (Figures 3A and S7). In addition, the time course assay shows the kinetics of covalent complex formation are on par with the overall cleavage rate (Figure 3B).

We also examined the reactivity of OTUD1 toward the branched probes. In vitro, it has been shown that OTUD1 displays moderate selectivity toward Lys63-linked chains. ${ }^{52}$ We found that OTUD1 cleaves the native Lys63 linkage in probes 11b and 11b*, leaving behind a diUb ABP with a warhead at position-48 (Figure 3C). By contrast, when the warhead is at position-63 (11d*) a covalent adduct is readily observed. Together, these results demonstrate 
that certain DUBs can selectively react with branched ABPs, similar to what has been observed with di-Ub probes.

Lastly, we investigated the reactivity of branched probes toward E3 ligases bearing activesite Cys residues. Two HECT E3 ligases were chosen: UBE3C and AREL1. The purpose here was not to assess whether the E3s display selectivity toward certain probes since these enzymes synthesize heterotypic Ub chains containing a mixture of linkages. ${ }^{53-55}$ Instead, we wanted to measure the efficiency of labeling for future structural studies aiming to identify cryptic Ub binding sites that are important for chain assembly. With both UBE3C and ARE1L, we detected the formation of a covalent adduct between probes $11 \mathbf{a}, \mathbf{1 1 b}$, and 11d*, and the catalytic domains of UBE3C and AREL1 only when the catalytic Cys is present (Figures 4A,B and S8). In general, the labeling efficiency is higher with UBE3C compared to AREL1 (Figure S9). Interestingly, there does appear to be some selectivity. Probe 11c containing the warhead at position- 6 and an isopeptide bond at position-63 does not react with either UBE3C or ARE1L even though it does label nonselective DUBs, e.g., USP7, to some extent (Figure S10). This observation may reflect the linkage preferences of UBE3C and ARE1L considering Lys6 and Lys63 are not produced by these enzymes to a significant degree. ${ }^{53-55}$ These results demonstrate that, in addition to DUBs, the branched probes can be used to generate complexes with HECT ligases.

In conclusion, we report on the synthesis and reactivity of a new set of Ub ABPs based on branched trimers. To generate these probes, we devised an alternative synthetic approach to the Michael acceptor linking one arm of the branched trimer to the proximal subunit. The advances made include a facile cross-metathesis reaction and photodeprotection of a ketal. We found that like other Ub ABPs the branched probes readily react with E3 ligases and DUBs containing active-site Cys residues. These probes will be valuable tools for uncovering cryptic Ub binding sites on E3s and DUBs that lead to linkage selectivity in both chain assembly and disassembly.

\section{Supplementary Material}

Refer to Web version on PubMed Central for supplementary material.

\section{ACKNOWLEDGMENTS}

This work was supported by a research grant from the National Institutes of Health (RO1GM110543) and an NSF graduate research fellowship to K.K.D. (GRFP1451512). Mass spectral data were acquired at the University of Massachusetts Mass Spectrometry core facility. The Orbitrap Fusion was funded by NIH SIG S10OD010645. We thank Dr. Steve Eyles (UMass Amherst) for assistance with mass spectrometry.

\section{REFERENCES}

(1). Hershko A; Ciechanover A Annu. Rev. Biochem 1998, 67, 425-479. [PubMed: 9759494]

(2). Oh E; Akopian D; Rape M Annu. Rev. Cell Dev. Biol 2018, 34, 137-162. [PubMed: 30110556]

(3). Komander D; Rape M Annu. Rev. Biochem 2012, 81 (1), 203-229. [PubMed: 22524316]

(4). Swatek KN; Komander D Cell Res. 2016, 26 (4), 399-422. [PubMed: 27012465]

(5). Yau R; Rape M Nat. Cell Biol 2016, 18 (6), 579-586. [PubMed: 27230526]

(6). Mevissen TET; Komander D Annu. Rev. Biochem 2017, 86 (1), 159-192. [PubMed: 28498721] 
(7). Clague MJ; Urbe S; Komander D Nat. Rev. Mol. Cell Biol 2019, 20, 338-352. [PubMed: 30733604]

(8). Clague MJ; Barsukov I; Coulson JM; Liu H; Rigden DJ; Urbe S Physiol. Rev 2013, 93 (3), 1289_ 1315. [PubMed: 23899565]

(9). Husnjak K; Dikic I Annu. Rev. Biochem 2012, 81, 291-322. [PubMed: 22482907]

(10). Hewings DS; Flygare JA; Bogyo M; Wertz IE FEBS J. 2017, 284 (10), 1555-1576. [PubMed: 28196299]

(11). Witting KF; Mulder MPC; Ovaa HJ Mol. Biol 2017, 429 (22), 3388-3394.

(12). Cravatt BF; Wright AT; Kozarich JW Annu. Rev. Biochem 2008, 77 (1), 383-414. [PubMed: 18366325]

(13). Sanman LE; Bogyo M Annu. Rev. Biochem 2014, 83 (1), 249-273. [PubMed: 24905783]

(14). Hershko A; Rose IA Proc. Natl. Acad. Sci. U. S. A 1987, 84 (7), 1829-1833. [PubMed: 3031653]

(15). Pickart CM; Rose IA J. Biol. Chem 1986, 261 (22), 10210-10217. [PubMed: 3015923]

(16). Borodovsky A; Kessler BM; Casagrande R; Overkleeft HS; Wilkinson KD; Ploegh HL EMBO J. 2001, 20, 5187. [PubMed: 11566882]

(17). Borodovsky A; Ovaa H; Kolli N; Gan-Erdene T; Wilkinson KD; Ploegh HL; Kessler BM Chem. Biol 2002, 9 (10), 1149-1159. [PubMed: 12401499]

(18). Mulder MPC; Witting K; Berlin I; Pruneda JN; Wu KP; Chang JG; Merkx R; Bialas J; Groettrup M; Vertegaal ACO; et al. Nat. Chem. Biol 2016, 12 (7), 523-530. [PubMed: 27182664]

(19). Whedon SD; Markandeya N; Rana ASJB; Senger NA; Weller CE; Turecek F; Strieter ER; Chatterjee CJ Am. Chem. Soc 2016, 138 (42), 13774.

(20). Ekkebus R; Van Kasteren SI; Kulathu Y; Scholten A; Berlin I; Geurink PP; De Jong A; Goerdayal S; Neefjes J; Heck AJR; et al. J. Am. Chem. Soc 2013, 135 (8), 2867-2870. [PubMed: 23387960]

(21). Sommer S; Weikart ND; Linne U; Mootz HD Bioorg. Med. Chem 2013, 21 (9), 2511-2517. [PubMed: 23535560]

(22). Love KR; Catic A; Schlieker C; Ploegh HL Nature Chemical Biology; Nature Publishing Group, 2007; pp 697-705.

(23). Keusekotten K; Elliott PR; Glockner L; Fiil BK; Damgaard RB; Kulathu Y; Wauer T; Hospenthal MK; Gyrd-Hansen M; Krappmann D; et al. Cell 2013, 153, 1312-1326. [PubMed: 23746843]

(24). Kwasna D; Rehman SAA; Natarajan J; Matthews S; Madden R; De Cesare V; Weidlich S; Virdee S; Ahel I; Gibbs Seymour I; et al. Mol. Cell 2018, 70, 150-164. [PubMed: 29576527]

(25). Haahr P; Borgermann N; Guo X; Typas D; Achuthankutty D; Hoffman S; Shearer R; Sixma T; Mailand N Mol. Cell 2018, 70, 165-174. [PubMed: 29576528]

(26). Hewings DS; Heideker J; Ma TP; AhYoung AP; El Oualid F; Amore A; Costakes GT; Kirchhofer D; Brasher B; Pillow T; et al. Nat. Commun 2018, 9 (1), 1162. [PubMed: 29563501]

(27). Hermanns T; Pichlo C; Woiwode I; Klopffleisch K; Witting KF; Ovaa H; Baumann U; Hofmann K Nat. Commun 2018, 9 (1), 799. [PubMed: 29476094]

(28). Johnston SC; Riddle SM; Cohen RE; Hill CP EMBO J 1999, 18 (14), 3877-3887. [PubMed: 10406793]

(29). Hu M; Li P; Li M; Li W; Yao T; Wu J-W; Gu W; Cohen RE; Shi Y Cell 2002, 111, 1041. [PubMed: 12507430]

(30). Misaghi S; Galardy PJ; Meester WJN; Ovaa H; Ploegh HL; Gaudet RJ Biol. Chem 2005, 280 (2), $1512-1520$.

(31). Boudreaux DA; Maiti TK; Davies CW; Das C Proc. Natl. Acad. Sci. U. S. A 2010, 107 (20), 9117-9122. [PubMed: 20439756]

(32). Sahtoe DD; VanDijk WJ; ElOualid F; Ekkebus R; Ovaa H; Sixma TK Mol. Cell 2015, 57 (5), 887-900. [PubMed: 25702870]

(33). VanderLinden RT; Hemmis CW; Schmitt B; Ndoja A; Whitby FG; Robinson H; Cohen RE; Yao T; Hill CP Mol. Cell 2015, 57 (5), 901-911. [PubMed: 25702872]

(34). Mevissen TET; Kulathu Y; Mulder MPC; Geurink PP; Maslen SL; Gersch M; Elliott PR; Burke JE; Van Tol BDM; Akutsu M; et al. Nature 2016, 538, 402-405. [PubMed: 27732584] 
(35). McGouran JF; Gaertner SR; Altun M; Kramer HB; Kessler BM Chem. Biol 2013, 20 (12), 14471455. [PubMed: 24290882]

(36). Mulder MPC; El Oualid F; Ter Beek J; Ovaa H ChemBioChem 2014, 15, 946-949. [PubMed: 24623714]

(37). Li G; Liang Q; Gong P; Tencer AH; Zhuang Z Chem. Commun 2014, 50, 216.

(38). Haj-Yahya N; Hemantha HP; Meledin R; Bondalapati S; Seenaiah M; Brik. Org. Lett 2014, 16 (2), 540-543. [PubMed: 24364494]

(39). Paudel P; Zhang Q; Leung C; Greenberg HC; Guo Y; Chern Y-H; Dong A; Li Y; Vedadi M; Zhuang Z; et al. Proc. Natl. Acad. Sci. U. S. A 2019, 116, 7288. [PubMed: 30914461]

(40). Flierman D; Van Der Heden Van Noort GJ; Ekkebus R; Geurink PP; Mevissen TET; Hospenthal MK; Komander D; Ovaa H Cell Chem. Biol 2016, 23 (4), 472-482. [PubMed: 27066941]

(41). Meyer HJ; Rape M Cell 2014, 157 (4), 910-921. [PubMed: 24813613]

(42). Yau RG; Doerner K; Castellanos ER; Haakonsen DL; Werner A; Wang N; Yang XW; MartinezMartin N; Matsumoto ML; Dixit VM; et al. Cell 2017, 171 (4), 918-933. [PubMed: 29033132]

(43). Ohtake F; Tsuchiya H; Saeki Y; Tanaka K Proc. Natl. Acad. Sci. U. S. A 2018, 115, E1401E1408. [PubMed: 29378950]

(44). Liu C; Liu W; Ye Y; Li W Nat. Commun 2017, 8, 1-15. [PubMed: 28232747]

(45). Deol KK; Lorenz S; Strieter ER Front. Physiol 2019, DOI: 10.3389/fphys.2019.00835.

(46). Wertz IE; Newton K; Seshasayee D; Kusam S; Lam C; Zhang J; Popovych N; Helgason E; Schoeffler A; Jeet S; et al. Nature 2015, 528 (7582), 370-375. [PubMed: 26649818]

(47). Ohtake F; Saeki Y; Ishido S; Kanno J; Tanaka K Mol. Cell 2016, 64 (2), 251-266. [PubMed: 27746020]

(48). Michel MA; Komander D; Elliott PR Enzymatic Assembly of Ubiquitin Chains In The Ubiquitin Proteasome System. Methods in Molecular Biology; Humana Press, Inc.: New York, 2018; pp 73-84.

(49). Vedrenne E; Dupont H; Oualef S; Elkaim L; Grimaud L Synlett 2005, 4, 670-672.

(50). Edelmann MJ; Iphofer A; Akutsu M; Altun M; di Gleria K; Kramer HB; Fiebiger E; DhePaganon S; Kessler BM Biochem. J 2009, 418 (2), 379-390. [PubMed: 18954305]

(51). Wiener R; Dibello AT; Lombardi PM; Guzzo CM; Zhang X; Matunis MJ; Wolberger C Nat. Struct. Mol. Biol 2013, 20 (9), 1033-1039. [PubMed: 23955022]

(52). Ritorto MS; Ewan R; Perez-Oliva AB; Knebel A; Buhrlage SJ; Wightman M; Kelly SM; Wood NT; Virdee S; Gray NS; et al. Nat. Commun 2014, 5, 1-11.

(53). Michel MA; Elliott PR; Swatek KN; Simicek M; Pruneda JN; Wagstaff JL; Freund SMV; Komander D Mol. Cell 2015, 58 (1), 95-109. [PubMed: 25752577]

(54). Kristariyanto YA; Abdul Rehman SA; Campbell DG; Morrice NA; Johnson C; Toth R; Kulathu Y Mol. Cell 2015, 58 (1), 83-94. [PubMed: 25752573]

(55). Kristariyanto YA; Choi S-Y; Rehman SAA; Ritorto MS; Campbell DG; Morrice NA; Toth R; Kulathu Y Biochem. J 2015, 467 (2), 345-352. [PubMed: 25723849] 

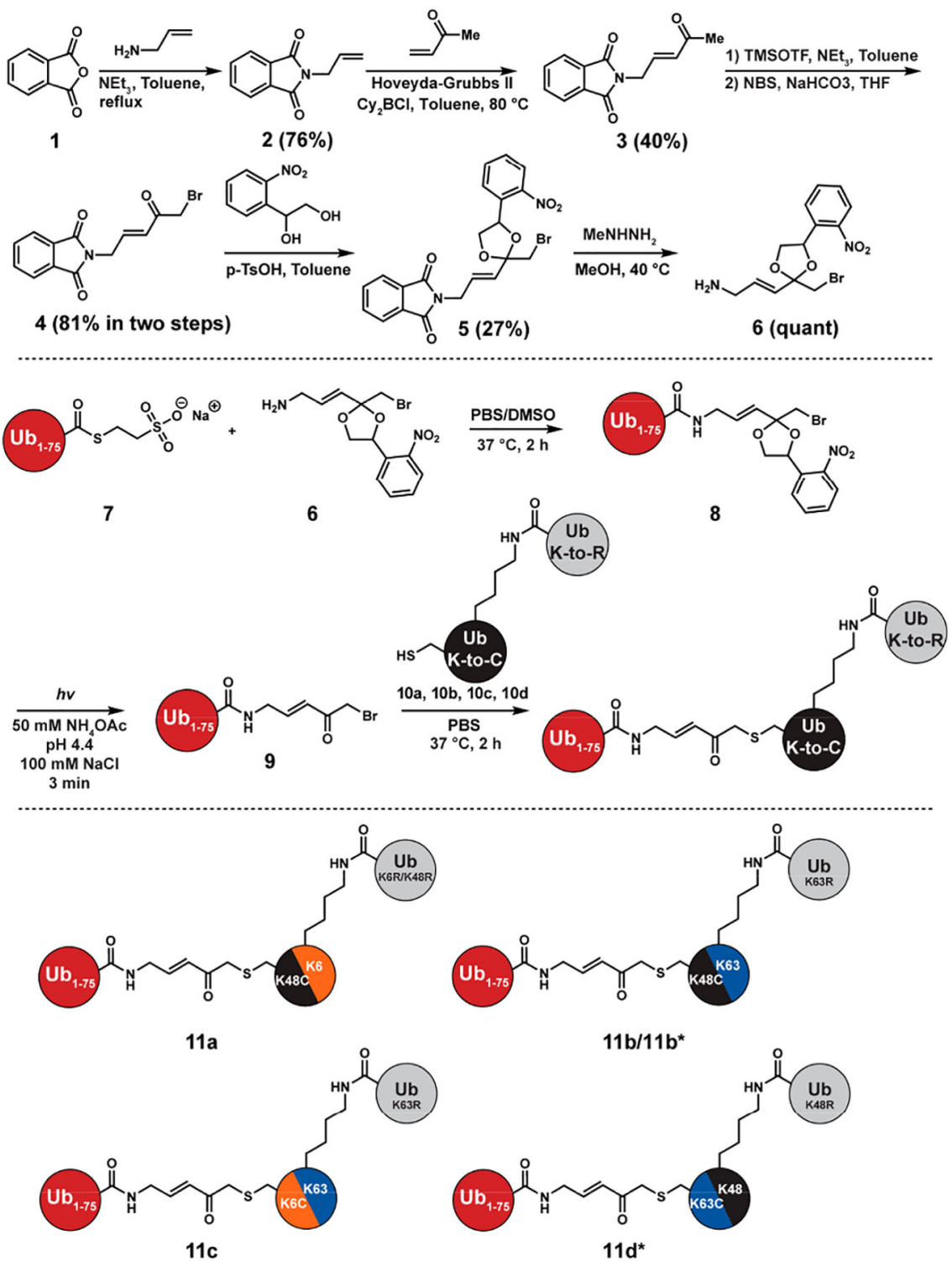

Figure 1.

Synthesis of Ub-BVK and tri-Ub ABPs. Di-Ub variants 10a and 10b contain a K48C substitution in the proximal Ub subunit and a native isopeptide bond at position- 6 or -63 , respectively. 10c contains a $\mathrm{K} 6 \mathrm{C}$ substitution in the proximal and a native isopeptide bond at position-63 (Lys63-linked). 10d is a Lys48-linked dimer with a K63C substitution in the proximal subunit. 11b* is a branched tri-Ub probe where the distal Ub attached to position-48 is N-terminally biotinylated. 11d* is a branched tri-Ub probe where the distal $\mathrm{Ub}$ attached to position-63 is N-terminally biotinylated. 
A
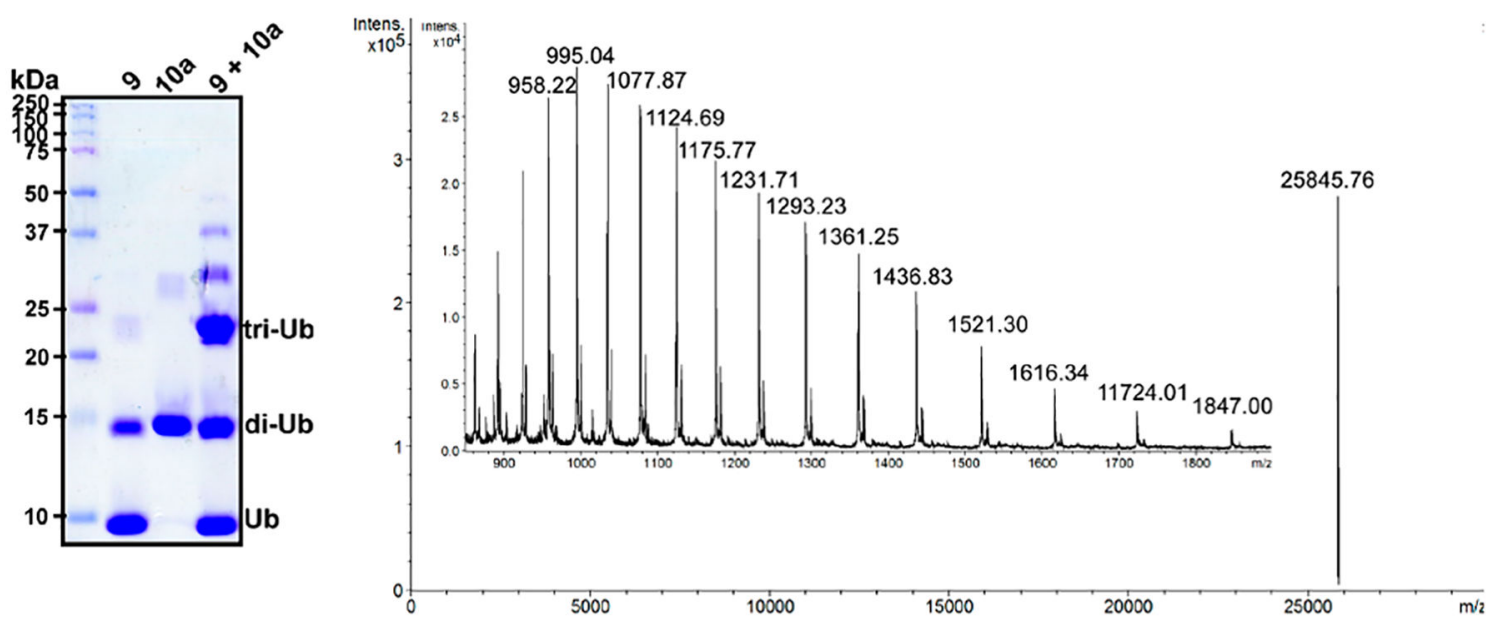

B
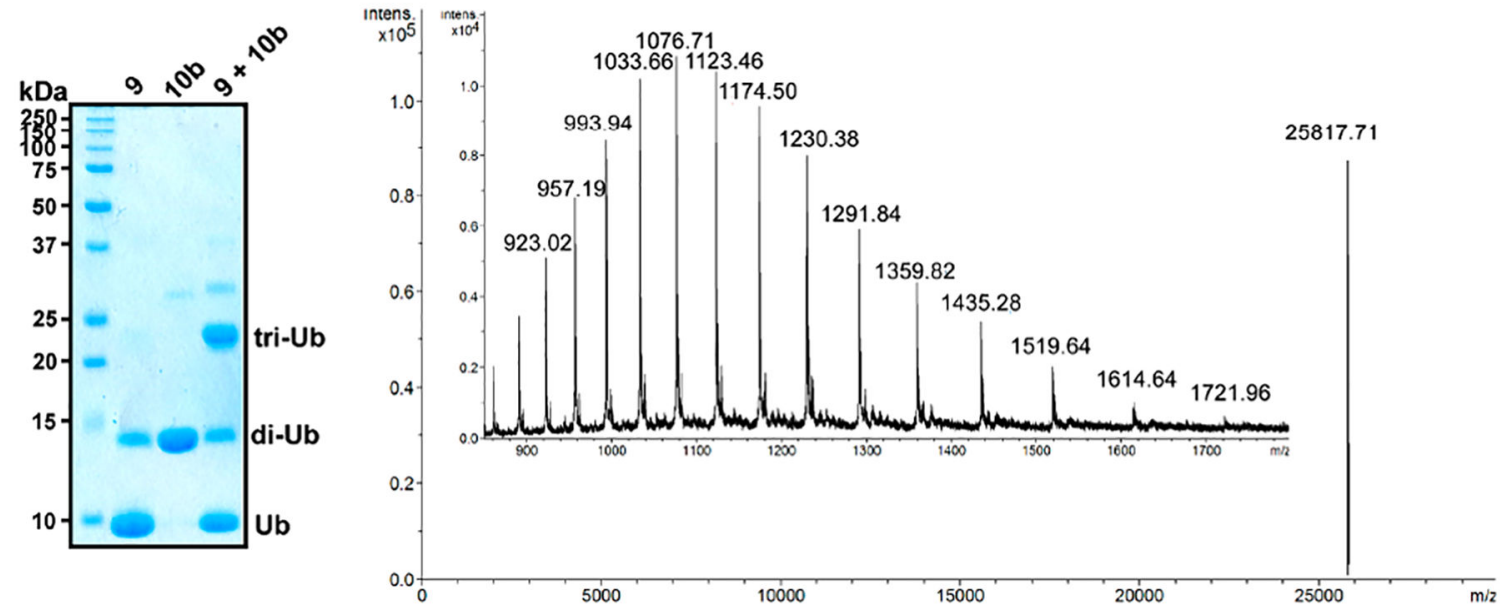

Figure 2.

Representative SDS-PAGE and MS analysis of tri-Ub ABPs. (A) Coomassie-stained SDSPAGE gel showing the formation of probe 11a using Ub-BVK and di-Ub 10a. ESI-MS analysis of purified 11a (observed deconvoluted $\mathrm{m} / \mathrm{z}$ ratio for $[\mathrm{M}+\mathrm{H}]^{+}$is 25845.8 ; calculated $\mathrm{m} / \mathrm{z}$ is 25846.6 ). The di-Ub species present along with Ub-BVK 9 is formed by self-condensation of Ub-MESNa 7 while concentrating the sample. (B) SDS-PAGE gel showing the formation of $\mathbf{1 1 b}$ starting from Ub-BVK and di-Ub 10b. ESI-MS analysis of purified 11b (observed deconvoluted $\mathrm{m} / \mathrm{z}$ ratio for $[\mathrm{M}+\mathrm{H}]^{+}$is 25817.7 ; calculated $\mathrm{m} / \mathrm{z}$ is 25817.1). 


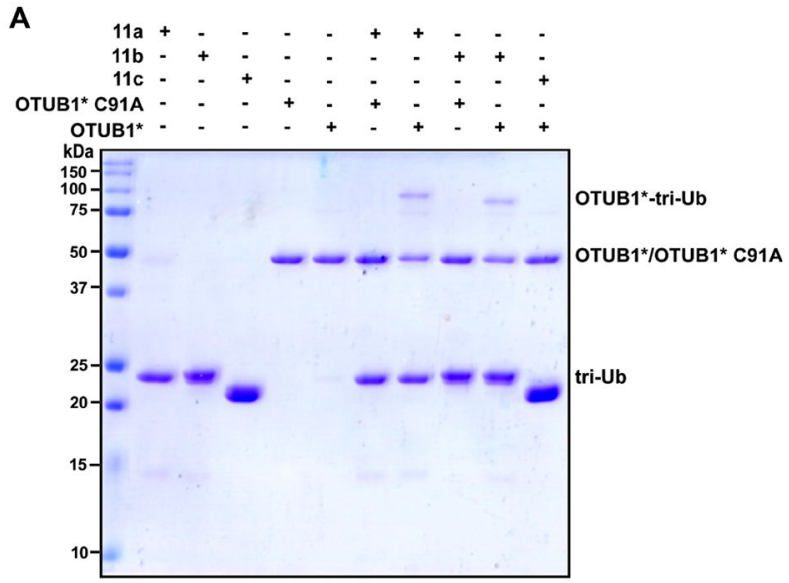

B

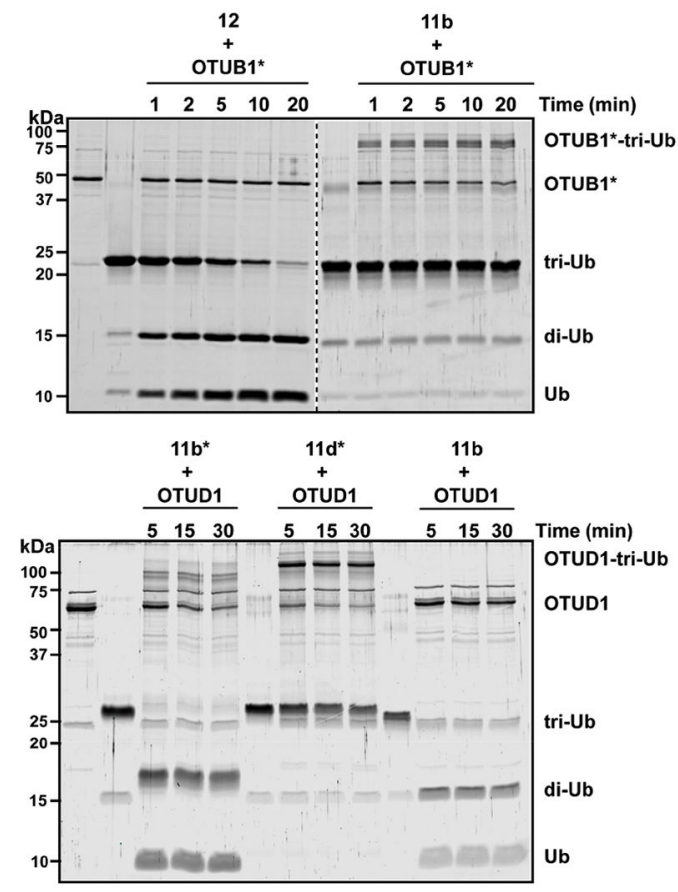

Figure 3.

Labeling DUBs with branched tri-Ub probes. (A) Coomassie-stained SDS-PAGE gel showing the reaction between tri-Ub probes 11a-c and either active or inactive $(\mathrm{C} 91 \mathrm{~A})$ OTUB1*. Probes were incubated with OTUB1* for $5 \mathrm{~min}$ at room temperature.(B) SYPRO Ruby-stained SDS-PAGE gel showing the cleavage of native K48/K63 tri-Ub (12) by OTUB $1 *$ over time at $37^{\circ} \mathrm{C}$ (left side of the gel). Right side shows the labeling of OTUB1* with the 11b probe at $37^{\circ} \mathrm{C}$. (C) SYPRO Ruby-stained SDS-PAGE gel showing the labeling of OTUD1 with different tri-Ub probes. Reactions were performed at $37{ }^{\circ} \mathrm{C}$. 

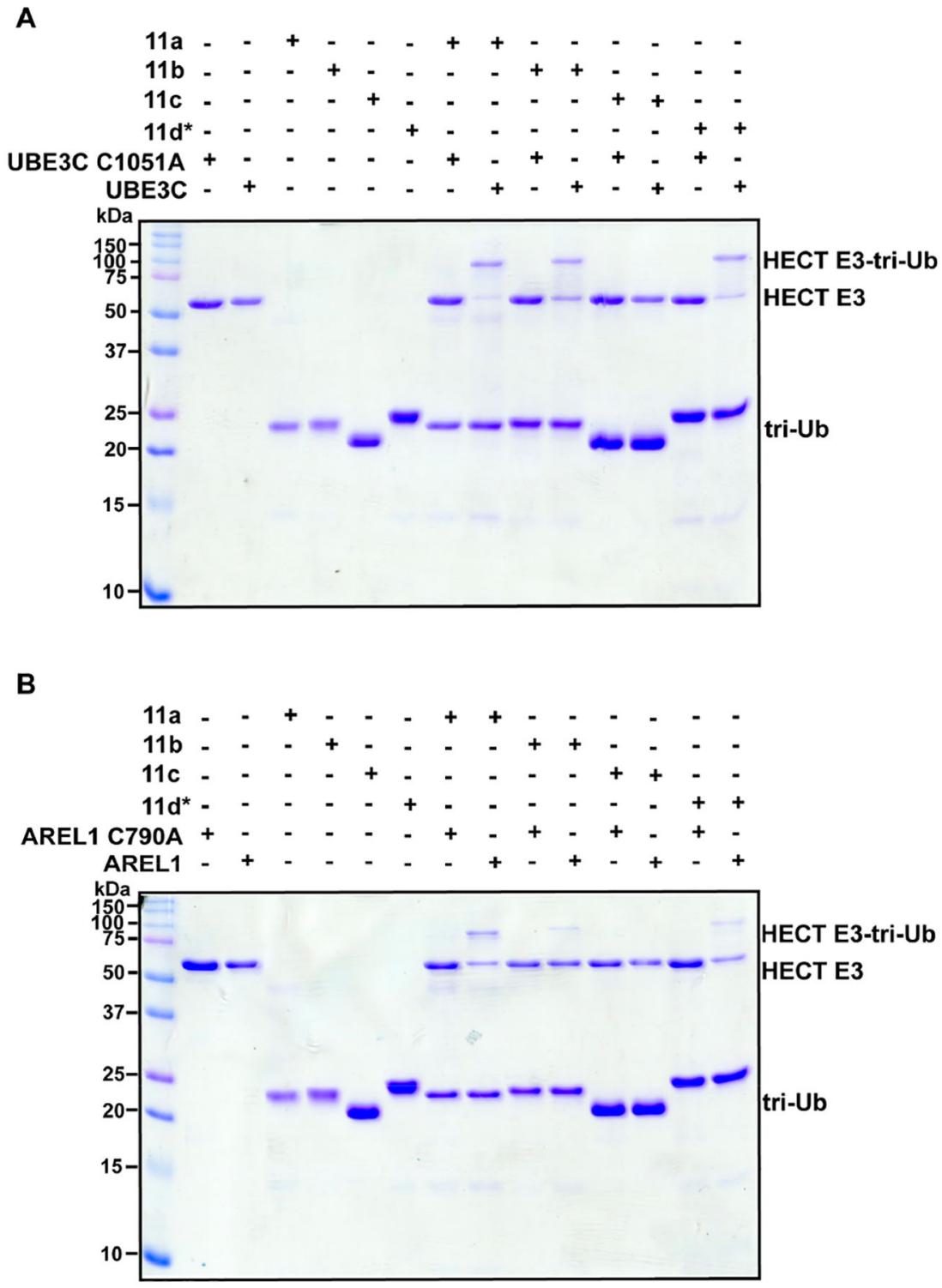

Figure 4.

Labeling of HECT E3 ligases with branched tri-Ub probes. Coomassie-stained SDS-PAGE gel showing the formation of a covalent complex between the branched ABPs 11a, 11b, and 11d* and active, but not inactive, UBE3C (A) and AREL1 (B). 

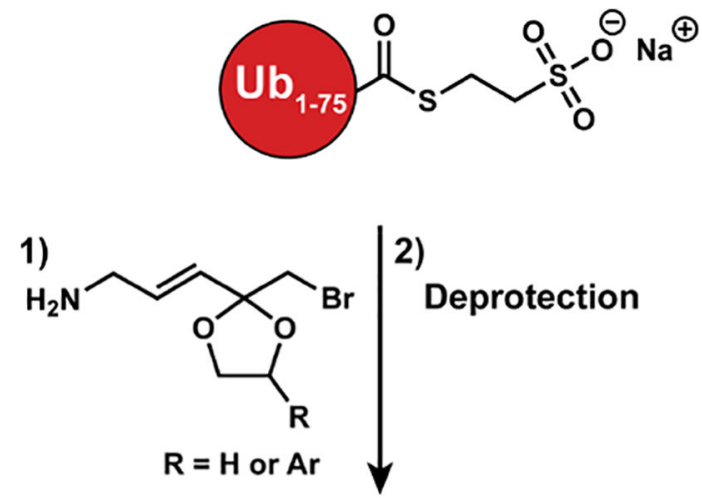

Hs K-to-C

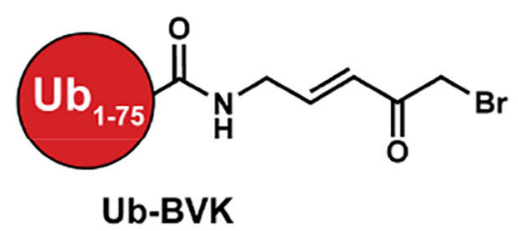
Ub K-to-R mutant

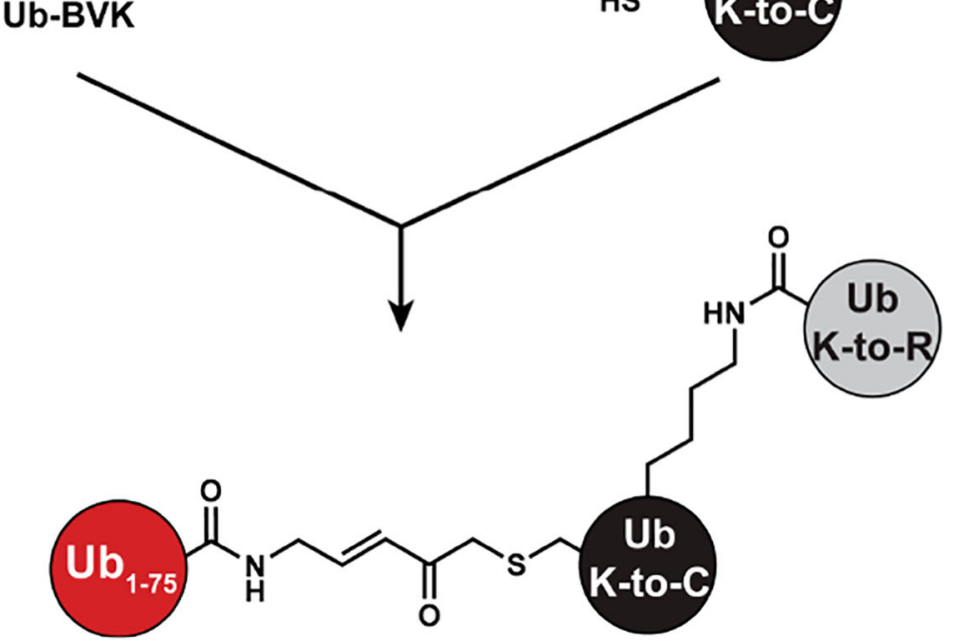

Scheme 1.

Strategy for Generating Branched Tri-Ub ABPs 